\title{
The predictive value of bleeding score on the diagnosis of Von Willebrand disease in children applied to the hematologic clinic with epistaxis
}

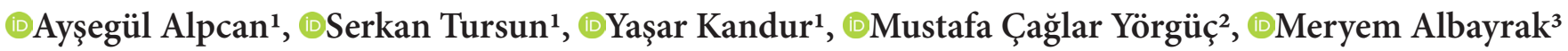 \\ ${ }^{1}$ Kırıkkale University, School of Medicine, Department of Pediatrics, Kırıkkale, Turkey \\ ${ }^{2}$ Medicana International Hospital, Department of Pediatrics, Ankara, Turkey \\ ${ }^{3}$ Kırıkkale University, School of Medicine, Department of Pediatric Hematology and Oncology, Kırıkkale, Turkey
}

Cite this article as: Alpcan A, Tursun S, Kandur Y, Yörgüç MÇ, Albayrak M. The predictive value of bleeding score on the diagnosis of von Willebrand disease in children applied to the hematologic clinic with epistaxis. J Health Sci Med 2022; 5(1): $22-25$.

\begin{abstract}
Aim: Epistaxis may be a symptom of an inherited bleeding disease.. We aimed to analyze an approved pediatric bleeding score (PBS) as a screening test for von Willebrand Disease (VWD) in children with epistaxis

Material and Method: We retrospectively reviewed the medical records of pediatric patients, who applied to the Pediatric Hematology Department with the complaint of epistaxis between January 2018 and December 2019.

Results: One hundred and sixty eight patients enrolled in this study There were 65(38.7\%) girls and 103(61.3\%) boys, with a mean age of $114 \pm 49$ months (range 8 months to 18 years).The PBS of 34 patients was greater than/ or equal to 2 . Factor 8 , von Willebrand factor antigen, and von Willebrand Ristocetin cofactor levels were significantly lower in patients with $P B S \geq 2$ compared to those in patients with PBS $<2(\% 73 \pm 43$ vs $\% 91 \pm 29, p=0.03 ; 87 \pm 44$ vs $106 \pm 29 \mathrm{IU} / \mathrm{dl}, \mathrm{p}=0.03 ; 72 \pm 39$ vs $98 \pm 30 \mathrm{IU} /$ $\mathrm{dl}, \mathrm{p}=0.001$, respectively). While 15 (44\%) of 34 patients with $\mathrm{PBS} \geq 2$ diagnosed VWD, but in the group with $\mathrm{PBS}<2$, VWD was diagnosed for only 4 children $(0.02 \%)$ (4/134). The sensitivity, specificity, positive predictive value (PPV), and negative predictive value (NPV) of PBS for diagnosis of VWD was $79.0 \%, 87.2 \%, 44 \%$, and $97 \%$ respectively.

Conclusion: PBS could be integrated into the evaluation of children suspected of having a bleeding disorder such as VWD in pediatrician's offices. Our cut off value 2 appears to be significant in exclusion of VWD, since its high negative predictive value.
\end{abstract}

Keywords: Pediatric bleeding score, epistaxis, Von Willebrand disease

\section{INTRODUCTION}

Epistaxis is a common problem in the pediatric population and it can cause serious distress and anxiety among children and their parents. It may be a symptom of an inherited bleeding disease (1). Von Willebrand Disease (VWD), is a disease associated with bleeding diathesis especially epistaxis that is the most common symptom (2). Determining bleeding in diagnosing of VWD often poses a significant challenge in children. However, children may present epistaxis without the disease. Therefore, a coagulation test should not be performed on every patient with epistaxis and VWD should not be considered immediately. This standardization aims primarily to avoid unnecessary laboratory tests and to predict future risk of bleeding. For this reason, development of bleeding assessment tools has been studied in recent years to help to measure bleeding symptoms and to standardize bleeding histories $(3,4)$. Bowman et al. established and approved pediatric bleeding score (PBS) in 2009 to detect VWD. The PBS examine the presence and severity of bleeding symptoms including epistaxis, bleeding from minor wounds, easy bruising, oral cavity bleeding, bleeding after dental or surgical procedures, gastrointestinal tract bleeding, menorrhagia (5). The patient is questioned for epistaxis, easy bruising, bleeding after dental or surgical procedures and menorrhagia (6). Scoring is based on a scale from 0 to 4 in most categories, and - 1 to 4 in some categories, with representing the most severe symptoms (7). When PBS was administered to children with bleeding symptoms, the sensitivity and specificity for VWD were $83 \%$ and $79 \%$ respectively and the negative predictive value (NPV) was 99\% (5). In this study, we aimed to confirm PBS as a VWD screening tool in children with epistaxis admitted to the pediatrics hematology clinic of a tertiary referral hospital in middle Anatolia of Turkey. 


\section{MATERIAL AND METHOD}

The study protocol was approved by the Kirikkale University School of Medicine Non-Interventional Clinical Research Ethics Committee (Date: 07.08.2019, Decision No: 2019.08.05). All procedures were carried out in accordance with the ethical rules and the principles of the Declaration of Helsinki.

We retrospectively reviewed the medical records of pediatric patients, who applied to the pediatric hematology department with the complaint of epistaxis between January 2018 and December 2019. Data including demographic characteristics, medical history and family history of bleeding were recorded. Bleeding scores of all children were calculated. Following the physical examination, laboratory tests were performed: complete blood count, peripheral smear, blood type, bleeding time, prothrombin time (PT), partial thromboplastin time (aPTT), von Willebrand factor antigen (VWF:Ag) levels, Factor VIII (FVIII) level, and platelet function were analyzed with platelet function analyzer (PFA-100). The in-house enzyme-linked immunosorbent assays were applied for VWF:Ag as previously described (8). The in-house VWF ristocetin cofactor (VWF:RCo) assay (9) was performed to measure GpIb binding activity. FVIII coagulant activity (FVIII:C) assay (10) was conducted.

In this study, the participants with VWF levels, activities and/or antigen, of $<30 \mathrm{IU} / \mathrm{dL}$ were diagnosed as VWD (11). The patients with VWF levels of 30 to $50 \mathrm{IU} / \mathrm{dL}$ would be reclassified into low VWF according to the current concept (12). The patients with insufficient clinical information, acquired von Willebrand syndrome (AVWS), or diagnosis as other bleeding disorders rather than VWD were excluded. Patients with an organic pathology detected on ear, nose and throat examination, who used drugs, who had a primary disease leading to bleeding diathesis, traumatic epistaxis and the patients with hypertension were excluded from the study.

\section{Pediatric Bleeding Score (PBS)}

The patients evaluated with a total bleeding score equal and bigger than 2 accepted as having a bleeding disorder (5). The questions were answered by the parents of children, and also by themselves of the children aged 12 years and older. Patients were classified into two groups based on the PBS as follows: PBS bigger than/ or equal to 2 and PBS smaller than 2.

\section{Statistical Analysis}

SPSS for Windows (Version 16, USA) was used for data management and statistical analysis. The normality evaluation of the data was done with Shapiro Wilk test. The continous variables were presented as mean $\pm \mathrm{SD}$ and the categorical variables were presented as number (percentage). The comparison of continuous variables between two groups were done with student $t$ test or Mann Whitney $U$ test according to distribution normality of data and categorical variables were compared between two groups with Chi Square test. Sensitivity, specificity, and positive and negative predictive value of PBS score for the diagnosis of VWD were calculated. A p-value smaller than 0.05 was accepted as statistically significant.

\section{RESULTS}

One hundred and sixty eight patients enrolled in this study There were 65(38.7\%) girls and 103(61.3\%) boys, with a mean age of $114 \pm 49$ months (range 8 months to 18 years)

The PBS of 34 patients was greater than/ or equal to 2 . The mean age of these 34 patients was $110 \pm 50$ months (range 24-204 months). We compared the demographic and hematological parameters of patients with $\mathrm{PBS}<2$ $(n=134)$ and $P B S \geq 2(n=34)$. Factor 8, VWFAg, and VWFR co levels were significantly lower in patients with $\mathrm{PBS} \geq 2$ compared to those in patients with $\mathrm{PBS}<2(\% 73 \pm 43$ vs $\% 91 \pm 29, \mathrm{p}=0.03 ; 87 \pm 44$ vs $106 \pm 29 \mathrm{IU} / \mathrm{dl}, \mathrm{p}=0.03 ; 72 \pm 39$ vs $98 \pm 30 \mathrm{IU} / \mathrm{dl}, \mathrm{p}=0.001$, respectively). The remaining demographic and hematological parameters did not show a significant difference between patients with either PBS $\geq 2$ or not (Table 1 ).

\begin{tabular}{|c|c|c|c|}
\hline Parameter & $\begin{array}{c}\text { Pediatric } \\
\text { bleeding } \\
\text { score }<2 \\
n=134\end{array}$ & $\begin{array}{c}\text { Pediatric } \\
\text { bleeding } \\
\text { score } \geq 2 \\
n=34\end{array}$ & P value \\
\hline Age (months) & $115 \pm 49$ & $110 \pm 50$ & 0.6 \\
\hline Female/Male (n/n) & $51 / 83$ & $14 / 20$ & 0.84 \\
\hline Platelet $\left(\mathrm{x} 10^{3}\right)$ & $302 \pm 71$ & $322 \pm 72$ & 0.18 \\
\hline Hemoglobin (gr/dL) & $13 \pm 1.2$ & $12.8 \pm 1.1$ & 0.27 \\
\hline Prothrombin time (seconds) & $10.8 \pm 4.5$ & $11.4 \pm 3$ & 0.46 \\
\hline Fibrinogen $(\mathrm{mg} / \mathrm{dL})$ & $252 \pm 65$ & $174 \pm 87$ & 0.16 \\
\hline APTT (seconds) & $27 \pm 9.1$ & $29.4 \pm 6.6$ & 0.15 \\
\hline Factor VIII (\%) & $91 \pm 29$ & $73 \pm 43$ & 0.03 \\
\hline VWFAg (IU/dl) & $106 \pm 29$ & $87 \pm 44$ & 0.03 \\
\hline VWFRCo (IU/dl) & $98 \pm 30$ & $72 \pm 39$ & 0.001 \\
\hline PFA-100 & $109 \pm 18$ & $127 \pm 74$ & 0.24 \\
\hline Bleeding time (minutes) & $2.1 \pm 1.3$ & $4.7 \pm 3.7$ & 0.44 \\
\hline
\end{tabular}

While 15 (44\%) of 34 patients with $\mathrm{PBS} \geq 2$ diagnosed VWD, but in the group with $\mathrm{PBS}<2$, VWD was diagnosed for only 4 children (0.02\%) (4/134). The PBS, demographic characteristics, VWF, Ristocetin and Factor VIII levels of the 15 patients were given in Table 2. Seven of them have had the diagnosis of VWD. The remaining 8 children have taken into follow-up for the possibility of development of VWD. 


\begin{tabular}{|cccccc|}
\hline \multicolumn{5}{|c|}{$\begin{array}{c}\text { Table 2. } \\
\text { Willebrand disease patients with pediatric bleeding score } \geq 2\end{array}$} \\
\begin{tabular}{|cccccc} 
Patient \\
No
\end{tabular} & $\begin{array}{c}\text { Age } \\
\text { (months) }\end{array}$ & $\begin{array}{c}\text { Family } \\
\text { history }\end{array}$ & $\begin{array}{c}\text { F VIII } \\
\text { (IU/dl) }\end{array}$ & $\begin{array}{c}\text { VWF-Ag } \\
\text { (IU/dl) }\end{array}$ & $\begin{array}{c}\text { VWF:Ricof } \\
\text { (IU/dl) }\end{array}$ \\
\hline 1 & 86 & + & 33 & 50 & 27 \\
2 & 139 & - & 32 & 43 & 21 \\
3 & 162 & - & 49 & 50 & 47 \\
4 & 64 & - & 42 & 20 & 30 \\
5 & 152 & + & 21 & 51 & 61 \\
6 & 12 & + & 26 & 34 & 36 \\
7 & 160 & - & 28 & 90 & 148 \\
8 & 180 & + & 20 & 16 & 10 \\
9 & 60 & + & 29 & 41 & 33 \\
10 & 50 & - & 31 & 72 & 29 \\
11 & 96 & - & 41 & 16 & 64 \\
12 & 141 & - & 42 & 114 & 69 \\
13 & 73 & - & 24 & 39 & 22 \\
14 & 118 & + & 42 & 46 & 61 \\
15 & 142 & + & 44 & 59 & 37 \\
\hline
\end{tabular}

The PBS, demographic characteristics, VWF, Ristocetin and Factor VIII levles of the 4 patients with $\mathrm{PBS}<2$ were given in Table 3.

Table 3. Demographic and laboratory characteristics of 4 Von Willebrand disease patients with pediatric bleeding score $<2$

\begin{tabular}{|cccccc|}
\hline $\begin{array}{c}\text { Patient } \\
\text { No }\end{array}$ & $\begin{array}{c}\text { Age } \\
\text { (months) }\end{array}$ & $\begin{array}{c}\text { Family } \\
\text { history }\end{array}$ & $\begin{array}{c}\text { F VIII } \\
\text { (IU/dl) }\end{array}$ & $\begin{array}{c}\text { VWF-Ag } \\
\text { (IU/dl) }\end{array}$ & $\begin{array}{c}\text { VWF:Ricof } \\
\text { (IU/dl) }\end{array}$ \\
\hline 1 & 36 & Brother+ & 37 & 135 & 88 \\
2 & 192 & - & 20 & 40 & 32 \\
3 & 120 & - & 36 & 49 & 24 \\
4 & 62 & Brother + & 25 & 42 & 29 \\
\hline
\end{tabular}

Number of patients with a diagnosis of VWD according to PBS scores were given in Table 4.

\begin{tabular}{|c|c|c|}
\hline Parameter & VWD (+) $n=19$ & VWD (-) $n=149$ \\
\hline $\mathrm{PBS} \geq 2(\mathrm{n} / \%)$ & $15(79.0)$ & $19(12.8)$ \\
\hline PBS <2 (n/\%) & $4(21.0)$ & $130(87.2)$ \\
\hline Total & 19 & 149 \\
\hline
\end{tabular}

The sensitivity, specificity, positive predictive value (PPV), and negative predictive value (NPV) of PBS for diagnosis of VWD was $79.0 \%, 87.2 \%, 44 \%$, and $97 \%$ respectively.

\section{DISCUSSION}

In our study, we found that the PBS cut-off value 2 is meaningful to predict VWD in pediatric patients experiencing epistaxis. According to our knowledge, this study is the first in the literature evaluating PBS in only pediatric patients with complaint of epistaxis. This study showed the effectiveness of PBS to diagnose theVWD in pediatric patients with epistaxis.
Beyond being used as a screening test in the primary healthcare services, PBSs can be used to assess and document the severity of bleeding in the referral setting and as part of the initial diagnostic approach. A metaanalytic study suggested the use of a validated PBS rather than a non-standardized clinical assessment as an initial screening test to determine who needs specific blood tests for patients with a low probability of VWD (e.g. seen in primary care setting) (13).

Previous studies showed that a clinically significant bleeding score of $\geq 2$ can be applied in the discrimination of "normal" and "mild hemorrhagic diseases (14-16). In these studies the high NPV and receiver operating characteristic (ROC) data show that PBS can be used in advance to differentiate between VWD and normal children. Another study from our country (17) showed that the cut off level of 2 is suitable forTurkish population in differential diagnosis of "mild bleeding disorders" and "hemostatically normal patients with symptoms". Bowman et al. (5) showed that a cut off value of PBS above 2 in patients with bleeding history (bleeding from minor wounds, epistaxis, easy bruising, and menorrhagia), the sensitivity, specificity, PPV, and NPV were found to be $83 \%, 79 \%, 14 \%$, and $99 \%$, respectively near similar to our results. While we found a positive predictive value of $44 \%$ of the VWD in patients with PBS value of $\geq 2,0.02 \%$ of patients with low PBS were diagnosed VWD. Therefore the negative predictive value of scoring was higher.

There is no single test that can diagnose VWD. Measurement of VWF antigen, von Willebrand factor ristocetin cofactor activity, factor VIII clotting activity, and measurement of VWF multimers lead to the diagnosis of VWD. Obtaining these tests in populationbased screening would be not a cost-benefit analysis (18). So that PBS usage may convenient in first visit differential diagnosis of bleeding disorders, especially VWD.

We think that non-invasive clinical approaches that disable the use of invasive methods could be applied in the diagnosis of such a common autosomal dominant disease. If the bleeding history is evaluated with PBS, it will provide a prediction for advanced blood tests in selected patients. The PBS may not detect mild cases. However, due to its high NPV, it prevents unnecessary tests that is also cost-effective. By this, inappropriate laboratory testing, over-treatment and, distressing venepuncture in children would be prevented. We think that PBS can be applied in primary care medicine.

Our study has the following limitations. Firstly, its retrospective design could not indicate the true prevalence and diagnosis of VWD. And secondly this study conducted on a single center, so it could not project the true prevalence belongs to total population. 


\section{CONCLUSION}

PBS could be integrated into the evaluation of children suspected of having a bleeding disorder such as VWD in pediatrician's offices. Our cut off value appears to be significant in exclusion of VWD, since its high negative predictive value. So that in patients with the suspicion of VWD and a PBS $\geq 2$, the diagnosis should be supported by coagulation laboratory tests.

\section{ETHICAL DECLARATIONS}

Ethics Committee Approval: The study protocol was approved by the Kırıkkale University School of Medicine Non-Interventional Clinical Research Ethics Committee (Date: 07.08.2019, Decision No: 2019.08.05).

Informed Consent: Because the study was designed retrospectively, no written informed consent form was obtained from patients.

Referee Evaluation Process: Externally peer-reviewed.

Conflict of Interest Statement: The authors have no conflicts of interest to declare.

Financial Disclosure: The authors declared that this study has received no financial support.

Author Contributions: All of the authors declare that they have all participated in the design, execution, and analysis of the paper, and that they have approved the final version.

\section{REFERENCES}

1. Sandoval C, Dong S, Visintainer P, Ozkaynak MF, Jayabose S. Clinical and laboratory features of 178 children with recurrent epistaxis. J Pediatr Hematol Oncol 2002; 47-9.

2. Recht M, Chitlur M, Lam D. Epistaxis as a common presenting symptom of Glanzmann's thrombasthenia, a rare qualitative platelet disorder: illustrative case examples. Case Rep Emerg Med 2017; 2017: 8796425.

3. Natalia Rydz, Paula D James. The evolution and value of bleeding assessment tools. J Thromb Haemost 2012; 10: 2223-9.

4. Sarah H O'Brien. Bleeding scores: are they really useful? Hematology Am Soc Hematol Educ Program 2012; 2012: 152-6.

5. Bowman M, Riddel J, Rand ML, Tosetto A, Silva M, James PD. Evaluation of the diagnostic utility for von Willebrand disease of a pediatric bleeding questionnaire. J Thromb Haemost 2009; 7: 1418-21.

6. Bui J, Martyres D, James PD, et al. Validation of the school age self-administered pediatric bleeding questionnaire (Self-PBQ) in children aged 8-12 years. Pediatr Blood Cancer 2019; 66:e27709

7. Tosetto A, Rodeghiero F, Castaman G, et al. A quantitative analysis of bleeding symptoms in type 1 von Willebrand disease: results from a multicenter European study (MCMDM-1 VWD). J Thromb Haemost 2006; 4: 766-73.

8. Rojnuckarin P, Akkawat B, Intragumtornchai T. Von Willebrand factor (VWF) antigen levels and function in healthy Thais. Southeast Asian J Trop Med Public Health 2005; 36: 1292-7.

9. Macfarlane DE, Stibbe J, Kirby EP, Zucker MB, Grant RA, McPherson J. Letter: a method for assaying von Willebrand factor (ristocetin cofactor). Thromb Diath Haemorrh 1975; 34: 306-8.
10. Kitchen S, Gray E, Mertens K. Monitoring of modified factor VIII and IX products. Haemophilia 2014; 20: 36-42.

11. Nichols WL, Hultin MB, James AH, et al. Von Willebrand disease (VWD): evidence-based diagnosis and management guidelines, the National Heart, Lung, and Blood Institute (NHLBI) Expert Panel Report (USA). Haemophilia 2008; 14: 171-232.

12.Leebeek F, Eikenboom J. Von Willebrand's disease. N Engl J Med 2016; 375: 2067-80.

13. James PD, Connell NT, Ameer B, et al. ASH ISTH NHF WFH 2021 guidelines on the diagnosis of von Willebrand disease. Blood Adv 2021; 5: 280-300.

14. Tosetto A, Rodeghiero F, Castaman G, et al. A quantitative analysis of bleeding symptoms in type 1 von Willebrand disease: results from a multicenter European study (MCMDM-1 VWD). J Thromb Haemost 2006; 4: 766-73.

15. Tosetto A, Castaman G, Rodeghiero F. Bleeding scores in inherited bleeding disorders: clinical or research tools? Haemophilia 2008; 14: 415-22.

16. Biss TT, Blanchette VS, Bowman M, et al. Quantification of bleeding symptoms in children with von Willebrand disease or a platelet function disorder: use of a standardized pediatric bleeding score. Blood 2007; 110: 636a.

17. Belen B, Kocak U, Isik M, et al. Evaluation of pediatric bleeding questionnaire in Turkish children with Von Willebrand disease and platelet function disorders. Clin Appl Thromb Hemost 2015; 21: 565-9.

18. Malec LM, Moore CG. Validation study of the composite score to identify Von Willebrand disease in children. J Pediatr Hematol Oncol 2016; 38: 139-42. 